\title{
Investigation of the LoRa Transceiver in Conditions of Multipath Propagation of Radio Signals
}

Dmytro Kucherov ${ }^{1, *}$, Andrei Berezkin ${ }^{2}$, Volodymyr Nakonechnyi ${ }^{3}$, Olha Sushchenko ${ }^{4}$, Ihor Ogirko ${ }^{5}$, Olha Ogirko ${ }^{6}$, Ruslan Skrynkovskyy ${ }^{7}$

${ }^{1}$ Department of Computerized Control Systems, National Aviation University, Kyiv, 03058, Ukraine

${ }^{2}$ Pukhov Institute for Modelling in Energy Engineering, National Academy of Science of Ukraine, Kyiv, 03164, Ukraine

${ }^{3}$ Department of Cyber Security and Information Protection, Taras Shevchenko National University, Kyiv, 01033, Ukraine

${ }^{4}$ Department of Aerospace Control Systems, Institute, National Aviation University, Kyiv, 03058, Ukraine

${ }^{5}$ Department of Mathematic, Kazimierz Pułaski University of Technology and Humanities in Radom, Radom, 26600, Poland

${ }^{6}$ Department of Information Technologies, Lviv State University of Internal Affairs, Lviv, 79020, Ukraine

${ }^{7}$ Department of Business Economy and Information Technology, Lviv University of Business and Law, Lviv, 79021, Ukraine

\section{A R T I C L E I N F O}

Article history:

Received: 08 November, 2020

Accepted: 09 February, 2021

Online: 16 February, 2021

Keywords:

Radio communication

Underground propagation

LoRa module

\begin{abstract}
A B S T R A C T
The article presents some results of the research of the LoRa module. These modules can be the basis of possible IoT technologies are implementing, providing enough good range of receiving and transmitting messages. The SX1276 transceiver has been testing to determine the signal loss in the propagation channel. These experiments took in a highlypopulated Kyiv district and one of the passageways of a Podbryantsevsky salt mine near the Solar town. The measured parameters are the maximum radio communication range in the mine, the signal-to-noise ratio, the number of bit errors and losses of the signal transmission. The data of the study we plan to use for the engineering of the radiomessaging networks based on LoRa radio modules.
\end{abstract}

\section{Introduction}

Multipath propagation is obtaining as a result of re-reflections of the signal source antenna beam from ground objects. Namely from buildings, a large number of rooms and corridors inside them, hills, vegetation, mine tunnels, etc., which create except the one direct some indirect directions of arrival of the beam. The receiving signal is an additive mixture of signals with different amplitudes, phases, and arrival directions. Multipath propagation of radio signals results in signal fading and frequency shift of the receiving signal.

Multipath propagation decreases the quality of the data reception. In the same circumstances, radar reception is resolved by introducing a small frequency additive into the low power oscillator of the frequency converter then receiving signal frequency deviation is synchronous with the transmitting signal frequency. The next way is the creation of additional reception

*Corresponding Author: Dmytro Kucherov, Email: d_kucherov@ukr.net channels. Another situation arises in technique for communicating, where noise has a strong effect, and the signal-to-noise ratio (SNR) is less than unity. A natural solution pointed problem is the complication of the receiving set by introducing additional receive channels and complex signal processing. However, this approach is not acceptable for the Internet of Things (IoT) technology. The peculiarity of the application of this technology in mines is the small size of antennas and equipment, also low power consumption.

Optimal filtering is one way to expand the SNR at the receiver output. However, in processing technology, this approach is not always suitable. The signal spectrum expands due to interference, and by increasing the acceptance threshold, and the signal may be lost. In this case, for improving the signal quality at the input of the matched filter, the noise protection is offered. Unluckily, wellknown methods of suppression of narrow-band interference do not apply as well. 
Due to its ability to maintain communications and lighting simultaneously, some authors consider the visible light communications (VLC) system like potential opportunity to implement effective communications in mines, which is basing on the phenomenon of light propagation. In this case, the quality of communication devices is highly dependent on the available channel propagation models, including long-term fading, which was critical for the project and assessing the operation of VLC systems. But, the basic features of the VLCs have not yet been enough explored. Also, dust and moisture block the propagation of light signals.

This paper is an extended version of our work [1] presented at the 2019 IEEE International Scientific-Practical Conference Problems of Infocommunications, Science and Technology (PIC S\&T) in which the research purpose was to study the features of LoRa (Long Range) signal processing in multipath propagation. The remaining part of the paper is organized as follows: Section 2 presents the works that provide an overview of the subject area; Section 3 devotes the general formulation of the problem; Section 4 briefly describes the features of the radio module when used in free space. Section 5 presents the results of module tests in multipath conditions, and conclusions from the studies are presented in Section 6.

\section{Paper Review}

Due to frequent disasters that occur in mining sites caused by landslides and rockslides of underground mine workings, the creation of a reliable system for communication in places of underground mining has recently become important.

In this case, the traditional solution is the use of radio communication systems. In the document [2], prepared in response to the MINER Act, an analysis of existing communication systems in different frequency ranges has been presented, and the basic requirements for existing radio communication facilities are formulating. Their functions are not only messaging but also tracking the actions of miners. Thus, radio communication is recognizing as the principal method of communication. In this respect, it is also worth noting that the work to establish the requirements for frequency ranges and radio communication range based on the study of the average attenuation characteristics of radio signals in mines of various types of minerals by this time was partially done (for example, see $[3,4]$ ).

Reviews of communication facilities in underground mines have also presented in papers $[5,6]$, where were manifest the problems of wireless communication under the ground, associated with attenuation and loss of communication that is greater than when they have on the surface. The attenuation parameter for a frequency of $900 \mathrm{MHz}$ has been refined in [7] and was concluding the possibility of using mobile communications in coal mines.

Recently, as an alternative to conventional wired and radio transmitting systems, researchers [8-11] are considering the possibility of using visible light as a means of communication for mine communication. So, in the article [8], based on this approach, a method is proposed for modeling the visible light propagation channel for two types of underground utilities: directly at the bottom hole and on the roadway, and the results of studies of the number of indicators spread signal in the visible light channel have presented. The main achievement of the authors of [9] is assessment loss as a function of distance.

In [10], the use of angular diversity receivers has been proposed that was focus on reducing inter-cell interference. It also considers new mathematical models of light distribution: pyramidal and hemi-dodecahedral. Numerical values for data rate, signal energy, and signal-to-noise-plus-interference ratio have also been presented, which can be useful for evaluating new solutions.

It is worth noting, the use of optics for communication has studied earlier. One of the earliest sources for time division multiple access (TDMA) broadcast communications dates back to 2005 [11]. Described here are a malfunction resistant system start and restart of the system with the dynamic self-configuration capability and a controlled internal diagnostic system.

The authors of $[12,13]$ propose the technology of detecting personnel and equipment in tunnels of underground manufactories by data transmission through light-emitting diodes and a photodetector; their approach also uses the trilateration method. So, in [12], an algorithm for determining the location of targeting objects is proposed. It is built based on data from several VLC systems located on the cover of an underground tunnel, as well as VLC mobile devices placed in the interests of ensuring the safety of miners, and the same problem is solved in three-dimensional space by authors [13].

To detect underground facilities, it is also possible to use ground penetration radar (GPR). So, in [14], it is proposed to divide the transmission paths into two types of signals: blocked and unblocked. Since the volume of blockaded signals is less than the estimated signal space, their routes are using in signal processing. A similar approach was proposed by the authors [15] based on the ULF (Ultra Low Frequency) radio channel for a mine specializing in the extraction of non-ferrous metals. In [16], GPR was used to assess soil moisture in the interests of agriculture. However, the range of propagation of electromagnetic waves underground is not long, does not exceed several meters; their use is advisable only in the interests of agriculture, which has been established by numerous studies and is confirming in [17 - 19]. The article [20] discusses the problems of robot navigation for coal mines.

This research continues the work presented in [21, 22].

\section{Problem Statement}

A multipath reception for a receiver based on LoRa technology is considering. In an open space, the module manufacturer guarantees the service of remote users at a distance of up to $20 \mathrm{~km}$ for a long life of the time, which makes the technology comparable with common Wi-Fi and LTE (Long-Term Evolution) [1].

The set of modules forms a system for picking reports from users and transmitting them to the server for further treatment and, maybe, answering queries. The messages exchanged between users; the service is providing by the open air at frequencies below GHz.

A message is a data package, which includes a preamble, a header and a payload, its size is dependent on the spreading factor 
$\left(S_{f}\right)$. Length of the package varied from 51 to 256 bits. The information transfer rate is between 22 and $27 \mathrm{kbps}$. The selection of this parameter depends upon the range, bandwidth and expansion factor. The signal that is emitted is a chirp signal, which is now assumed as the standard in the area of short-range wireless communication systems (IEEE 802.15.4a).

A distinguishing characteristic of signal receiving in multipath propagation is a significant deterioration in the signal quality, up to its complete loss. Examples of single radiation without interference and the total effect of four chirp signals without interference shown in Fig. 1, 2.

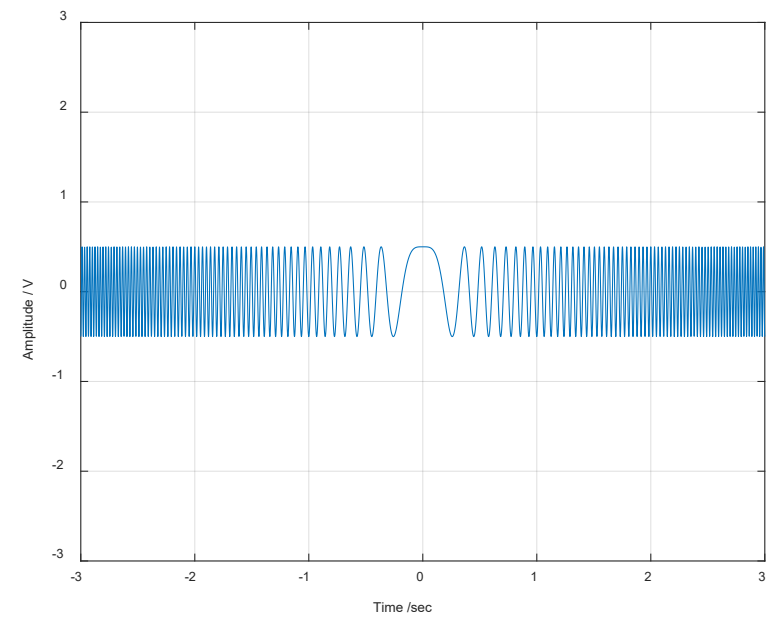

Figure 1: The one chirp signal

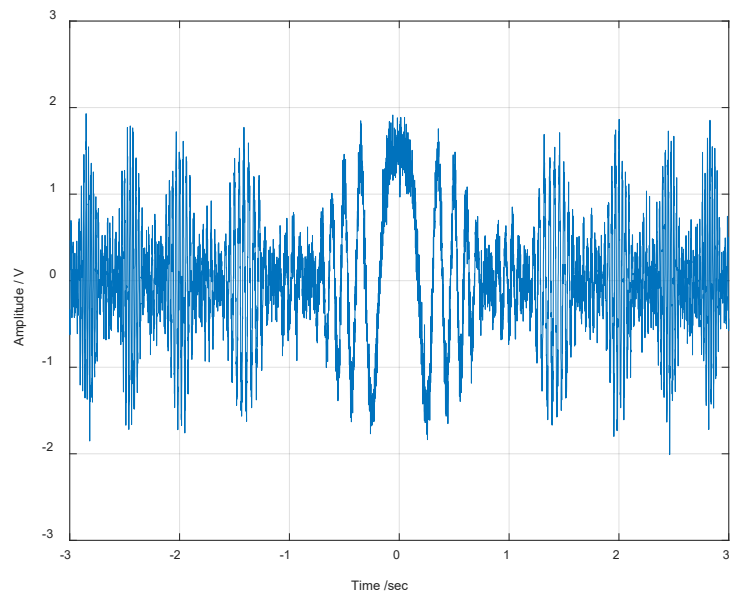

Figure 2: The four chirp signal with different phase shifts

A traditional study in the course of multipath reception is to clarify losses in the transmitter-receiver section and guarantee the receiving range [23]

$$
R=\sqrt{\frac{P_{t} F(\theta) G_{t} A_{r} e^{-2 \alpha d}}{4 \pi P_{r}}}
$$

where $R$ is the radio communication range; $P_{t}$ is the transmitter signal power; $F(\theta)$ is the antenna directivity in the $\theta$ direction, $F$ $(0)=1 ; G_{t}$ is the transmitting antenna gain; $A_{r}$ is the effective receiver area; $P_{r}$ is the signal power at the receiving set input; $\alpha$ is the attenuation of the signal along the path of the beam propagation, taking into account the free space and propagation environment; $d$ is the distance between two antennas.

Channel losses determine the budgeting of the wireless communication channel, which is calculated by the formula [23]:

$$
P_{r}=P_{t}+G_{t}-L_{s}-L_{c h}-M
$$

where $G_{t}$ is the gain determined by the directivity of the antennas, $L_{s}$ is the system's loss (for instance, in short antennas used in most remote devices), etc.; $L_{c h}$ is the loss in the signal spillover channel, $M$ is the attenuation signal is computed by empirical data. All values in the equation are expressing in $\mathrm{dB}$.

If we know value $R$ radio communication ranges in free space and the range in the loss conditions $D$, the value of losses in $\mathrm{dB}$ can be specified using the formula

$$
L=40 \lg \left(\frac{D}{R}\right)
$$

SNR and bit error (BER) rates are auxiliary indicators of reception quality. The SNR is determining as follows

$$
S N R=P_{\text {signal }} / P_{\text {noise }}=\left(a_{\text {signal }} / a_{\text {noise }}\right)^{2}
$$

The purpose of the research is to assess the effectiveness of using LoRa modules in a confined space, where it is possible to observe multipath propagation.

\section{Preliminary remarks}

A typical LoRaWAN radio network integrates end devices into architecture type a star. Messages are underlying double encrypted to ensure security. Devices that have small power consumption are ensuring by using a short time for transferring in a comparatively long time interval when the terminal device is in a "sleep" regime. Information is transferring both asynchronous and synchronous modes. The information from the end node of the network is spreading through the gateway to the network server and then deliver to the application server. LoRa modules have better receiver sensitivity because it uses chirp signals, error correction, high transmit noise immunity and insensibility to frequency changes of resonators.

In experiments, we used a module based on the SX1276 microcircuit (Fig. 3), in which messages are transmitting at a frequency of $868 \mathrm{MHz}$. Other parameters of the transceiver based on the SX1276 microcircuit [24] are presented in Table 1.

Table 1: Some parameters of SX1276

\begin{tabular}{|l|c|}
\hline Option & Value \\
\hline$\Delta f, \mathrm{kHz}$ & 20.8 \\
\hline$S_{f}$ & 8 \\
\hline $\mathrm{BR}, \mathrm{bps}$ & 1562 \\
\hline$P_{r}, \mathrm{dBm}$ & -128 \\
\hline
\end{tabular}

The channel budget, calculated by the formula (2), for a transmitter with a power of $100 \mathrm{~mW}$ in the case of ideal transmitreceive dipoles, for which the gain was chosen to be $2.1 \mathrm{~dB}$ and the minimum loss and signal attenuation turns out to be $130 \mathrm{~dB}$. 
The maximum range of radio communication in line-of-sight conditions for a lifting height of the receiving and transmitting antennas of $1 \mathrm{~m}$ under experiment conditions and normal refraction does not exceed $25 \mathrm{~km}$.

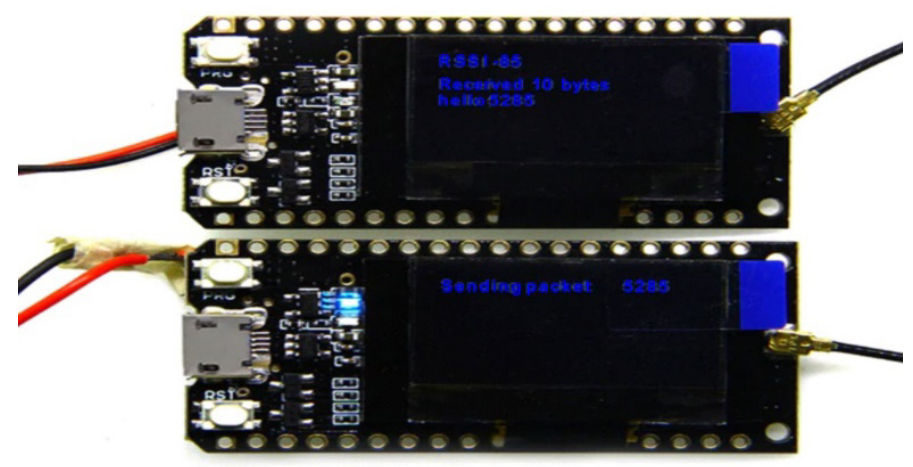

Figure 3: The module SX1276

The force of the received signal as a function of the range without interference [25, formula (5.15)] has shown in Fig. 4 with a blue line; the threshold sensitivity of the studied module is a black straight line. Crossing the lines gives the radio communication range corresponding to the real sensitivity of the receiving module, which turns out to be $4.8 \mathrm{~km}$.

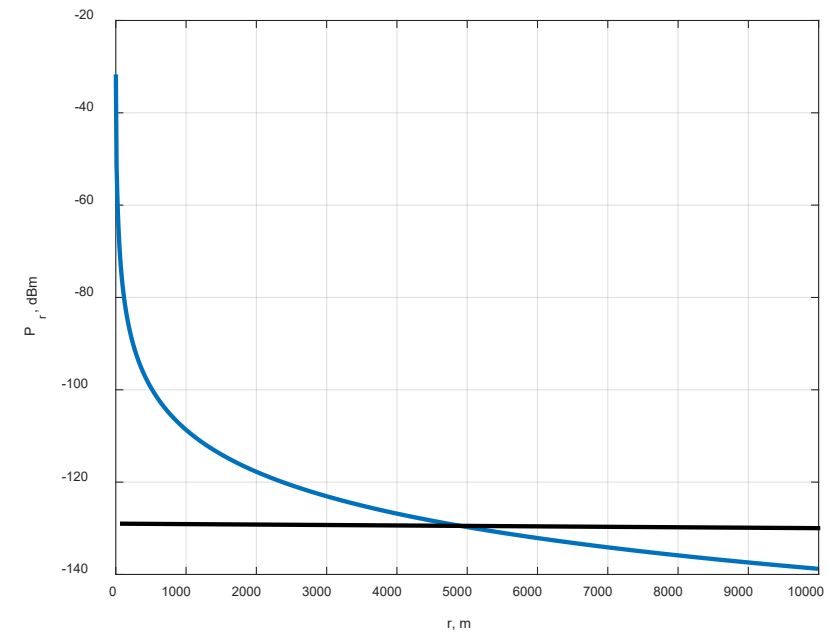

Figure 4: Estimation of the maximum radio communication range for a given sensitivity

\section{Research results}

The LoRa chipset study consisted of a sequence of surface experiments in a highly-populated city spot, where mobile communications and radio internet interfere with the receiving channel, and underground, in a mine where spurious radiation is absent. Ground tests based on a point-to-point scheme and a pointgateway with treatment on a remote server and underground tests were according to a point-to-point layout.

\subsection{Interference radio}

In the beginning, the transmitter installs on the last floor of a hard-wall building in Kyiv. A few Wi-Fi networks were deploying inside this building, on the roof of the building were also installed antennas of three operators' mobile communication. The indicator of the receiving device showed the message quality. At the experiment, the LoRa radio module was deposited from the 11th floor of the building to the first floor and to the downstairs located two floors below the first floor for creating multipath reception. The measurement framework reveals in Fig. 5. In Fig. 5, the abbreviations MS are used for the marking of the antenna of the stations of mobile operators, $\operatorname{Tr}$ is the transmitting module, $\mathrm{Rc}$ is the receiving device.

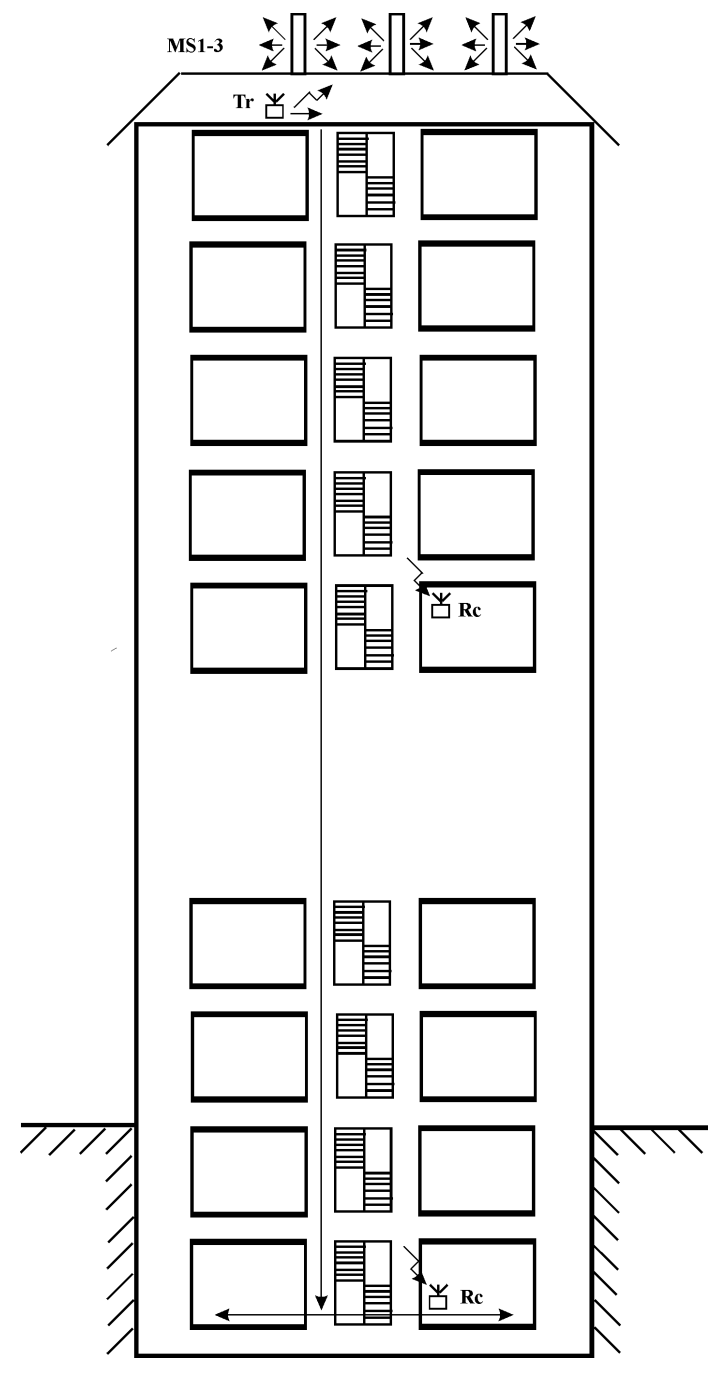

Figure 5: Layout of devices in the experiment

Rooftop antennas of mobile communications and Wi-Fi routers causing interference. These signals create a noise background, which chose as the "white". Crosstalk is causing by multiple reflections of beams inside the building from reinforced concrete structures. Using signal and noise level were fixed on every building floor, and the legibility of the text message was controlled as well. Additional documenting of the measurements has been carried out by a panoramic receiver, which chose as a reference. A initial report of the interference condition presents in Table 2.

The functioning of the transceiver in the "point-to-gateway" regime is fundamentally no different from the "point-to-point." The main difference is data processing, which carries out on a cloud server, and therefore the information has been slightly delayed (tens of milliseconds) compared to the point-to-point regime. In measurements, an auxiliary radio communication 
channel was used by a mobile phone. The results of measurements of the BER and SNR for the LoRa radio module shows in Fig. 6, 7 .

Table 2: Interference Condition

\begin{tabular}{|l|l|c|l|}
\hline $\begin{array}{c}\text { Type of } \\
\text { sources }\end{array}$ & Frequency, $\mathbf{M H z}$ & Power, $\boldsymbol{W}$ & Effect \\
\hline CDMA & $800-900$ & $2-60$ & strong \\
\hline LTE & $900-2400$ & $2-60$ & middle \\
\hline Wi-Fi & 2400 & 0,1 & weak \\
\hline Other & $400-5000$ & $<0,01$ & weak \\
\hline
\end{tabular}

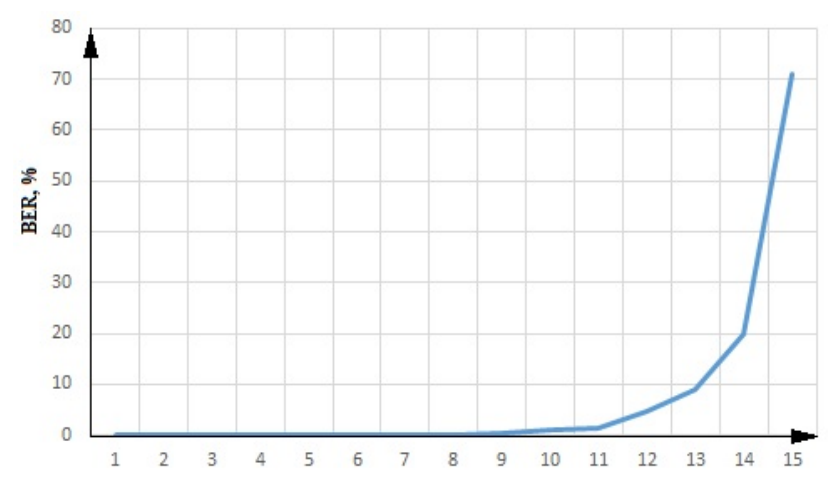

Figure 6: BER as a function of the number of the floor

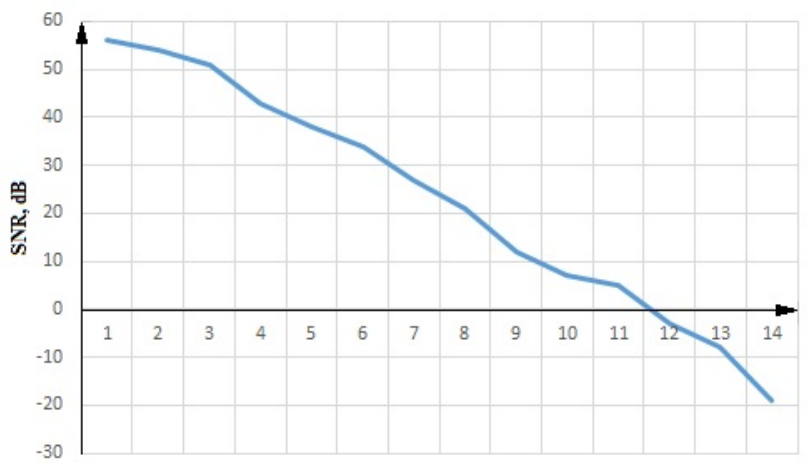

Figure 7: SNR as a function of the number of the floor.

By the experiment results, it has established that text messages receive on all floors and within $2 \mathrm{~m}$ from the staircase in the basement; the loss connection was at a distance of 8-10 $\mathrm{m}$ from the stairs.

\subsection{Using the LoRa module in a mine}

This subsection contains data on the results of measurements of the quality of message reception by the LoRa radio module at the conveyor slope of the Podbryantsevsky salt mine, located in the vicinity of the Soledar town.

The measurements were fulfilled in tunnels of the mine, in which are two parallel corridors connected by passages, Fig. 8. The experiment was carried out by step-by-step removal of the receiving set from a stationary transmitter with a fixed distance. The motion has been done from the initial point, corresponding to www.astesj.com the transmitter location, clockwise around the salt layer $23 \mathrm{~m}$ wide. The transmitter has installed $100 \mathrm{~m}$ from the comer.

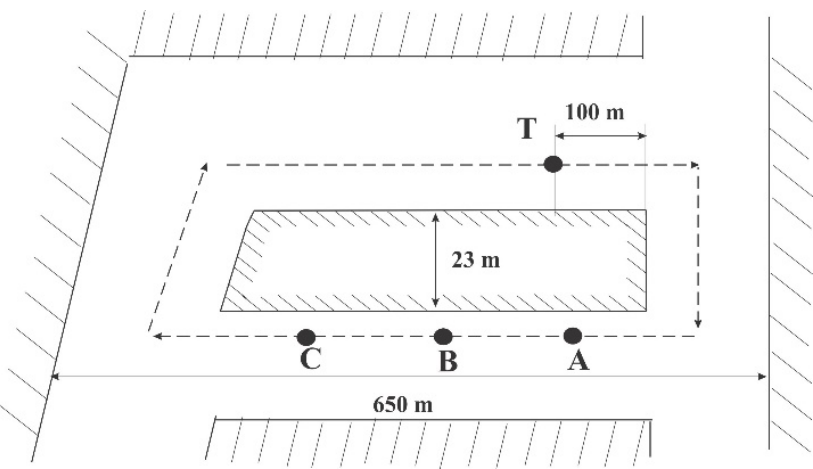

Figure 8: Section of the Podbryantsevsky formation mine, where measurements have been done

Point $\mathrm{A}$ in the diagram corresponds to a growth in the signal level around the comer, point $\mathrm{B}$ matches the signal maximum, and point $\mathrm{C}$ to a total signal loss. Also, the information in the mine was transmitted by voice; it was also repeated by the Motorola radio station functioning in the decimeter range and its output signal power of $1 \mathrm{~W}$.

The quality of communication in LoRa assesses by the number of packets received and by voice; the last way was estimated according to the degree of intelligibility of radio phrases. The results of the measurements present in Table 3 , where value $D$ is the distance from the LoRa receiving set to the transmitter antenna (T); Received Signal Strength Indicator (RSSI) serves as an indicator of the signal level at the receiving set input; Packets is the number of transmitted packets; Quality of Receiving is a category parameter of reception. The last parameter was the estimated sign "+" in case of satisfying reception, and "-" otherwise.

Table 3: Report of Receiving Quality

\begin{tabular}{|c|c|c|l|}
\hline $\boldsymbol{D}, \mathbf{m}$ & $\boldsymbol{R S S I}, \boldsymbol{d B m}$ & Packets & $\begin{array}{l}\text { Quality of } \\
\text { Receiving }\end{array}$ \\
\hline 100 & -94 & 4 & + \\
\hline 115 & -96 & 4 & + \\
\hline 129 & -107 & 4 & + \\
\hline $162(\mathrm{~A})$ & -98 & 4 & + \\
\hline 187 & -97 & 4 & + \\
\hline 211 & -96 & 4 & + \\
\hline $230(\mathrm{~B})$ & -93 & 4 & + \\
\hline 243 & -101 & 4 & + \\
\hline 263 & -113 & 4 & + \\
\hline 283 & -124 & - & \pm \\
\hline $303(\mathrm{C})$ & -128 & - & - \\
\hline
\end{tabular}

Based on the measurement data, a graph of the loss function $L(D)$ is built, where $D$ is the range from the signal source to the 
measurement point, Fig. 9. The resonant character of the curve in Fig. 9 is a consequence of the superposition of beams resulting from multipath propagation. Signal power losses in the section of indirect signal propagation with a length of $150-230 \mathrm{~m}$ have an average value of $15 \mathrm{~dB}$.

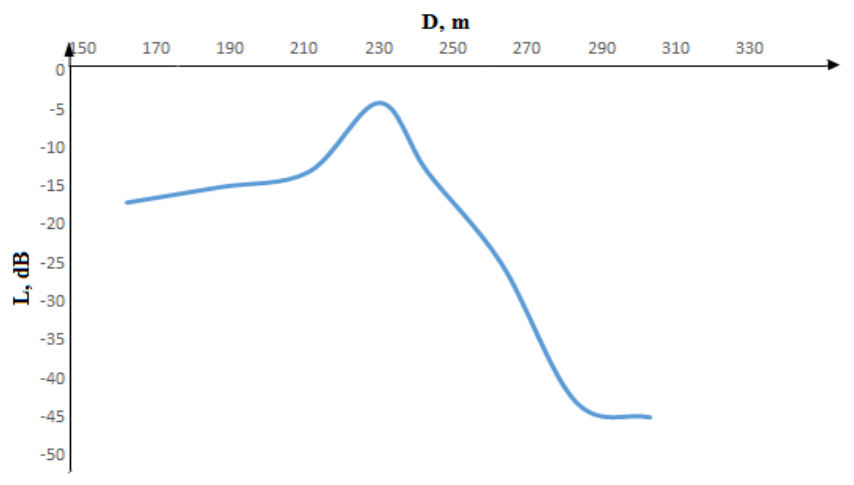

Figure 9: Graph of the function $L(D)$.

Analysis of various forms of communication in mine made it possible to establish that the range of voice communication, with due regard for phrasal awareness, no more than $30 \mathrm{~m}$; the distance of radio communication no more than $100 \mathrm{~m}$; the transmission range by LoRa reached $150 \mathrm{~m}$.

\section{Conclusions}

The paper presents a study of the LoRa module on two models of multipath propagation with external interference in a city building and without them in a salt mine. In the course of the studies carried out in a high-rise building, it was found that for the LoRa transmitter with a decrease in the SNR by $70 \mathrm{~dB}$, the BER deteriorates by only $15 \%$. The transmission range of messages in the mine with indirect beam propagation (Rayleigh channel) exceeded the distance of conventional radio communications by $30 \%$, voice communications by five times. The average loss at the frequency under consideration is $15 \mathrm{~dB}$ for a Rayleigh radio propagation channel, provided the messages are intelligible. These results are planning to be the basis for the choice of the LoRaWAN radio network topology as an element of mine communication.

\section{Conflict of Interest}

The authors declare no conflict of interest.

\section{Acknowledgment}

The authors thank both the authorities of the Taras Shevchenko National University, and National Aviation University the especially leadership of the Faculty of Cybersecurity, Computer and Software Engineering for their support during the preparation of this paper. The authors also thank the anonymous reviewers, whose comments significantly improved the content of the paper.

\section{References}

[1] D. Kucherov; A. Berezkin; O. Sushchenko, "Features of Signal Processing by Means of LoRa Technology," in 2019 IEEE International Scientific-Practical Conference Problems of Infocommunications, Science and Technology (PIC S\&T), Kyiv, Ukraine, $19-24, \quad 2019$. https://doi.org/10.1109/PICST47496.2019.9061410

[2] "Basic Tutorial on Wireless Communication and Electronic Tracking: Technology Overview," https://www.cdc.gov/niosh/mining/content/emergencymanagementandrespo nse/commtracking/commtrackingtutoriall.html

[3] T.S. Cory, Propagation of EM Signals In Underground Mines, Rockwell International Commercial Telecommunications Group, 1977. https://www.cdc.gov/niosh/mining/works/coversheet331.html

[4] T.S. Cory, R.J. Mahany, Mining Publication: Propagation of EM Signals in Underground Metal/Non-Metal Mines, U.S. Bureau of Mines, 1981. https://www.cdc.gov/niosh/mining/works/coversheet828.html

[5] J.N. Murphy, H.E. Parkinson, "Underground Mine Communications," P IEEE, 66 (1), 26-50, 1978. https://www.cdc.gov/NIOSH/mining/UserFiles/works/pdfs/umc.pdf

[6] S. Yarkan, S. Guzelgoz, H. Arslan, R.R. Murphy, "Underground Mine Communications: A Survey,” IEEE COMMUN SURV TUT, 11(3), 125-142, 2009. https://doi.org/10.1109/SURV.2009.090309

[7] Y.P. Zhang; G.X. Zheng; J.H. Sheng, "Radio propagation at $900 \mathrm{MHz}$ in underground coal mines," IEEE T ANTENN PROPAG, 49(5), 757-762, 2001. https://doi.org/10.1109/8.929630

[8] J. Wang, A. Al-Kinani, W. Zhang, and C.-X. Wang, "A New VLC Channel Model for Underground Mining Environments," in 2017 13th International Wireless Communications and Mobile Computing Conference (IWCMC), Valencia, Spain, 2017. https://doi.org/10.1109/IWCMC.2017.7986613

[9] J. Wang, A. Al-Kinani, J. Sun, W. Zhang, and C.-X. Wang, "A Path Loss Channel Model for Visible Light Communications in Underground Mines," in 2017 IEEE/CIC International Conference on Communications in China (ICCC), Qingdao, China, 2017. https://doi.org/10.1109/ICCChina.2017.8330479

[10] P.P. Játiva, M.R. Cañizares, C.A. Azurdia-Meza, D. Zabala-Blanco, A.D. Firoozabadi, F. Seguel, S. Montejo-Sánchez and I. Soto, "Interference Mitigation for Visible Light Communications in Underground Mines Using Angle Diversity Receivers," Sensors, 20 (2), 367, 1-29, 2020. https://doi.org/10.3390/s20020367

[11] T.-P. Wilfredo, Malekpour, Mahyar R., Miner, Paul S., "ROBUS-2: A FaultTolerant Broadcast Communication System," in NASA technical report, 2005, p. 188, https://ntrs.nasa.gov/citations/20050158766

[12] D. Iturralde, F. Seguel, I. Soto, C. Azurdia, S. Khan, "A new VLC System for Localization in Underground Mining Tunnels," IEEE LAT AM T, 15(4), 581587, 2017. https://doi.org/10.1109/TLA.2017.7896341

[13] A.D. Firoozabadi, C. Azurdia-Meza, I. Soto, F. Seguel, N. Krommenacker, D. Iturralde, P. Charpentier and D. Zabala-Blanco, "A Novel Frequency Domain Visible Light Communication (VLC) Three-Dimensional Trilateration System for Localization in Underground Mining," APPL SCI, 9(7), 1488; 1-15, 2019. https://doi.org/10.3390/app9071488

[14] S. Suherman, A.H. Rambe, E. Wijayanto and N. Mubarakah, "Received signal consideration for the through the earth radiobased underground object detection," J PHYS CONF SER, 1566, 1-7, 2020. https://doi.org/10.1088/1742-6596/1566/1/012003

[15] D.S. Kudinov, O.A. Maikov, E.A. Kokhonkova and V.S. Potylitsyn, "Development of a mathematical model and analysis of the receiver for emergency alerts in a mine," IOP CONF SER-MAT SCI, 862, 1-7, 2020. https://doi.org/10.1088/1757-899X/862/3/032111

[16] A. Salam, A. Ahmad, "Underground Soil Sensing Using Subsurface Radio Wave Propagation," Purdue e-Pubs, 255-260, 2019. https://docs.lib.purdue.edu/cit articles/19

[17] I.F. Akyildiz, E.P. Stuntebeck, "Wireless Underground Sensor Networks: Research Challenges," Ad Hoc Networks, 4, 669-686, 2006, https://doi.org/10.1016/j.adhoc.2006.04.003

[18] I.F. Akyildiz, Z. Sun, M.C. Vuran, "Signal Propagation Techniques for Wireless Underground Communication Networks," PHYS COMMUNAMST, 2(3), 167-183, 2009. https://doi.org/10.1016/j.phycom.2009.03.004

[19] N. Saeed, M.-S. Alouini, T.Y. Al-Naffouri, "Towards the Internet of Underground Things: A Systematic Survey," IEEE COMMUN SURV TUT, 21(4), 2019, 3443-3466. https://doi.org/10.1109/COMST.2019.2934365

[20] X. Chen, R. Liu, S. Zhang, H. Zeng, X. Yang, H. Deng, "Development of millimeter wave radar imaging and SLAM in underground coal mine environment,” J CHINA COAL SOC, 45(6), 2182-2192, 2020. https://doi.org/10.13225/j.cnki.jccs.ZN20.0316

[21] D. Kucherov, A. Berezkin, L. Onikienko, V. Nakonechnyi, "Processing Signals in The Receiving Channel for the Lora System," Data-centric business and applications. ICT Systems-Theory, Radio-Electronics, Information Technologies and Cybersecurity, 5, 423-445. https://doi.org/10.1007/978-3030-43070-2 19

[22] D. Kucherov, A. Berezkin, "Identification approach to determining of radio signal frequency," in Int. Conf. Antenna Theory and Techniques (ICATT) Kyiv, Ukraine, 2017. https://doi.org/10.1109/ICATT.2017.7972668

[23] B. Sklar, Digital Communications Fundamentals and Applications, Second Ed, Prentice Hall PTR, USA, 2002.

[24] SEMTECH SX1276. https://pdf1.alldatasheet.com/datasheetpdf/view/800239/SEMTECH/SX1276.html 